\section{(- OPEN ACCESS}

\title{
Effect of autologous adipose-derived mesenchymal stem cell therapy in the treatment of a post-traumatic chondral defect of the knee
}

\author{
Julien Freitag, ${ }^{1,2,3}$ Douglas Li, ${ }^{4}$ James Wickham, ${ }^{2}$ Kiran Shah, ${ }^{3}$ Abi Tenen ${ }^{3,5}$
}

${ }^{1}$ Melbourne Stem Cell Centre, Box Hill, Victoria, Australia ${ }^{2}$ School of Biomedical Sciences, Charles Sturt University-Orange Campus, Orange, New South Wales, Australia

${ }^{3}$ Magellan Stem Cells, Box Hill North, Victoria, Australia ${ }^{4}$ Orthopaedic Associates Melbourne, East Melbourne, Victoria, Australia

${ }^{5}$ Monash University, Clayton, Victoria, Australia

Correspondence to

Dr Julien Freitag,

julien.freitag@mscc.com.au

Accepted 15 September 2017

CrossMark

To cite: Freitag J, Li D,

Wickham J, et al. BMJ Case Rep Published Online First: [please include Day Month Year]. doi:10.1136/bcr-2017220852

\section{SUMMARY}

Isolated chondral defects have a limited capacity to heal and predispose to the development of osteoarthritis. Current surgical management can be unpredictable in outcome. Improved understanding of the action of mesenchymal stem cells (MSCs) has seen renewed interest in their role in cartilage repair. A 26-year-old athlete presented with a post-traumatic, isolated patella chondral defect. The patient underwent an arthroscopy with removal of a chondral loose body. After failure to symptomatically improve 12 months following surgery, the patient received intra-articular autologous adiposederived mesenchymal stem cell (ADMSC) therapy.

\section{BACKGROUND}

The management of post-traumatic isolated chondral defects poses a particular challenge to treating clinicians. It is recognised that articular cartilage has a limited capacity to heal. ${ }^{12}$ Furthermore, several studies have shown that isolated defects predispose a patient to later development of progressive and generalised degenerative osteoarthritis. ${ }^{34}$

The chosen management path for isolated chondral defects can be influenced by factors including patient age, partial-thickness or full-thickness chondral loss and the site of the lesion. Given the concern regarding early progression to osteoarthritis, surgical interventions are often considered. These can include, but are not limited to, arthroscopic debridement, microfracture/osteoplasty and, where appropriate, techniques such as autologous chondrocyte implantation (ACI) or matrix-induced autologous chondrocyte implantation (MACI).

Microfracture, otherwise known as osteoplasty, is a commonly used and accepted technique whereby holes are drilled or punched through the subchondral plate at the site of full-thickness cartilage loss and is designed to stimulate a healing response. It has been postulated that this method encourages the subsequent migration of bone marrow pluripotent stem cells to the area of injury creating an environment amenable to healing. ${ }^{5}$

Unfortunately while studies have successfully shown cartilaginous response at the site of microfracture, subsequent histological analysis has indicated type I fibrocartilage formation rather than hyaline cartilage. ${ }^{67}$ Additional studies have shown only fair to poor clinical outcome in long-term follow-up. ${ }^{8}$ Inadequate defect filling and reduced load-bearing properties of fibrocartilage have been postulated as the reasoning behind disappointing long-term outcome results. Additional understanding of the relative paucity of mesenchymal stem cells (MSCs) within bone marrow-as little as $0.001 \%$ in bone marrow aspirates-may also explain the inability to form hyaline-like cartilage. ${ }^{9} 10$

Chondrocyte implantation techniques such as $\mathrm{ACI}$ and MACI have shown encouraging results in the management of isolated chondral defects. Both preclinical and clinical trials have indicated hyalinelike cartilage regrowth, and correspondingly longterm clinical trials have observed encouraging durability in structure and patient outcome. ${ }^{11-15}$ The application of such interventions unfortunately remains limited due to the need to do additional surgery in harvesting the donor autograft cartilage, subsequent donor site morbidity and the observed poor integration of the grafted defect with the surrounding cartilage. ${ }^{16}$ The site of chondral defect has also influenced observed outcome. While reliable results are achieved with lesions involving the medial or lateral femoral condyle, lesions of the patellofemoral joint are not associated with such reproducible results. ${ }^{17}$

Given an improved understanding of the pathology of chondral defects, their inherent inability to heal and the limitations of current surgical management techniques, there has been renewed focus in the area of regenerative medicine techniques including MSCs. MSCs have the capacity to differentiate along a mesodermal cell lineage including adipocytes, osteoblasts and chondrocytes. ${ }^{18-20}$ In vitro studies have also shown that several growth factors-including transforming growth factor beta 1, insulin-like growth factor 1 and bone morphogenic proteins-can act synergistically to stimulate MSCs towards chondrocytes. ${ }^{21}$ Importantly, MSC-derived chondrocytes exhibit the same expression of type II collagen as mature adult chondrocytes. ${ }^{21}$

Whilst initial interest in the potential role of MSCs in joint repair was based on the evidence of their ability to differentiate into both cartilage and bone, it is now apparent that this may not be their primary path of action. Rather, it is anticipated that their ability to influence and stimulate healing may, in fact, be through paracrine mechanisms involving both immune-modulatory and trophic pathways. ${ }^{22-24}$ 
MSCs are observed to directly modulate the inflammatory response by the suppression of inflammatory T-cell proliferation and inhibition of monocyte and myeloid dendritic cell maturation. ${ }^{24}$ The acknowledged cascade of inflammatory pathways mediated by cytokines including interleukin 1 , tumour necrosis factor alpha and matrix metallopeptidases indicates the possible role that MSCs may have in inhibiting the cytokine lead degradation of cartilage. ${ }^{25-27}$

In addition, MSC secretion of essential reparative cytokines, including transforming growth factor beta, vascular endothelial growth factor and epidermal growth factor, may be responsible for a trophic effect resulting in local tissue repair. ${ }^{28-30}$ This trophic role, rather than direct chondrocyte transformation, is supported by the observation that in vitro coculture of MSCs with chondrocytes results in upregulation of collagen matrix formation, despite only minor chondrogenic differentiation of MSCs. ${ }^{31}$

Preclinical animal trials assessing chondral defect repair have indicated successful results using MSC-impregnated scaffolds. ${ }^{32}$ Histological analysis has also confirmed hyaline-like cartilage repair in chondral defects treated by microfracture in combination with MSC therapy. ${ }^{34} 35$ Furthermore, Lee and colleagues $^{36}$, in a surgically induced chondral defect porcine model, showed improved cartilage regeneration with the use of intra-articular injections of bone marrow-derived MSCs.

Within the human literature, there is supportive evidence of the potential efficacy of MSC in chondral defect management, though this has been limited to studies involving surgical implantation or cointervention. The use of MSC-impregnated scaffolds has resulted in both type II hyaline cartilage formation and equivalent results in direct comparison to ACI techniques. ${ }^{37} 38$ Histological and MRI analysis of chondral defects following arthroscopic subchondral drilling (a variant of microfracture) in combination with MSC therapy indicated statistically significant improvement in cartilage quality when compared with subchondral drilling without MSC therapy. ${ }^{39}$ The authors of this case report are involved in a current randomised controlled trial (RCT) on the use of MSCs in combination with microfracture in isolated chondral defects of the medial and lateral femoral condyle. $^{40}$

The preclinical and clinical investigation of the possible role of MSCs in the treatment of musculoskeletal conditions including chondral defects continues to grow. The National Institute of Health lists 652 current trials in the area of MSCs. ${ }^{41}$

\section{CASE PRESENTATION}

A 26-year-old national representative in karate presented with patellofemoral pain following a competition-related traumatic patella dislocation. The patient had manually reduced the patella. She was otherwise well and worked as a personal trainer.

Initial examination indicated an effusion, a positive patella apprehension test, reduced range in motion $\left(5^{\circ}-135^{\circ}\right)$ and stability on cruciate and collateral ligament testing. Subsequent MRI indicated features of previous patella dislocation with subchondral boney oedema of the patella and lateral femoral condyle and disruption of the medial patellofemoral ligament. The medial facet of the patella had evidence of a full-thickness chondral defect measuring $10 \mathrm{~mm}$ in width with a loose chondral body in the medial femoral gutter of the knee joint (figures 1 and 2).

The patient underwent arthroscopic surgery where the $10 \mathrm{~mm} \times 10 \mathrm{~mm}$ medial patella facet defect was noted and chondroplasty was performed to unstable areas of chondral surface.

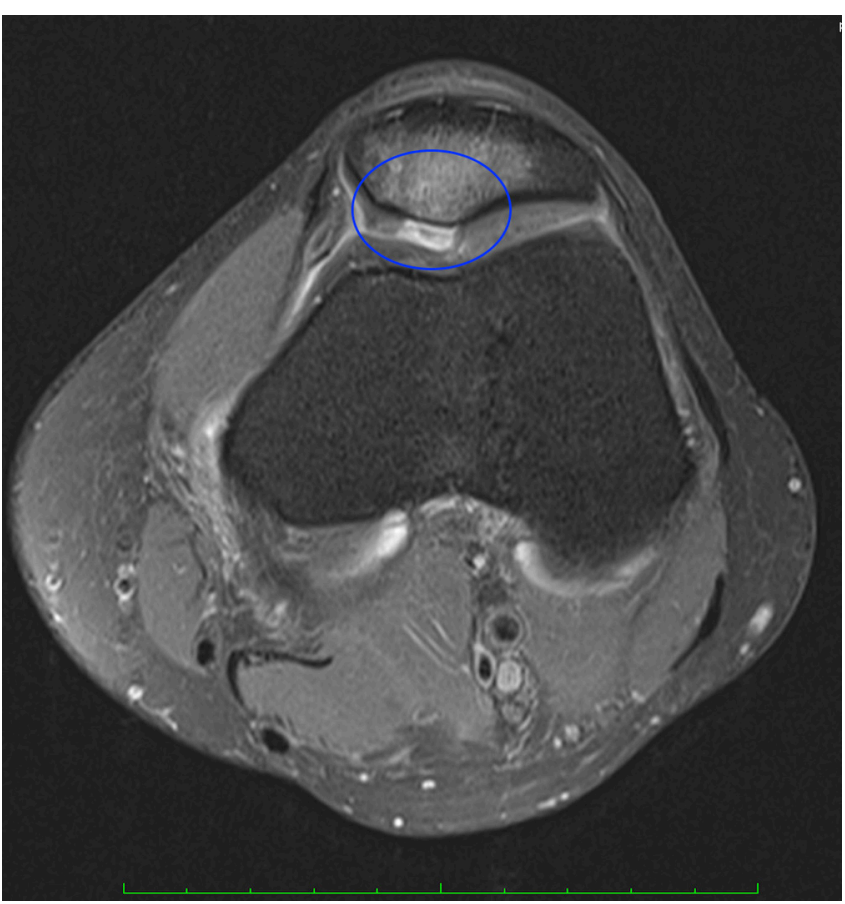

Figure 1 Proton density fat-suppressed MRI of the knee showing evidence of traumatic patella dislocation with subchondral boney oedema of the patella and a large chondral defect of the medial patella facet.

A small loose chondral body corresponding to the defect site was removed but was unable to be transplanted back due to size and the lack of an osteochondral layer. A medial longitudinal incision was made with repair of the medial patellofemoral ligament using a double-breasted suturing technique. The patient's knee was immobilised in a splint for a period of 2 weeks to protect the patellofemoral ligament repair, after which progressive range of

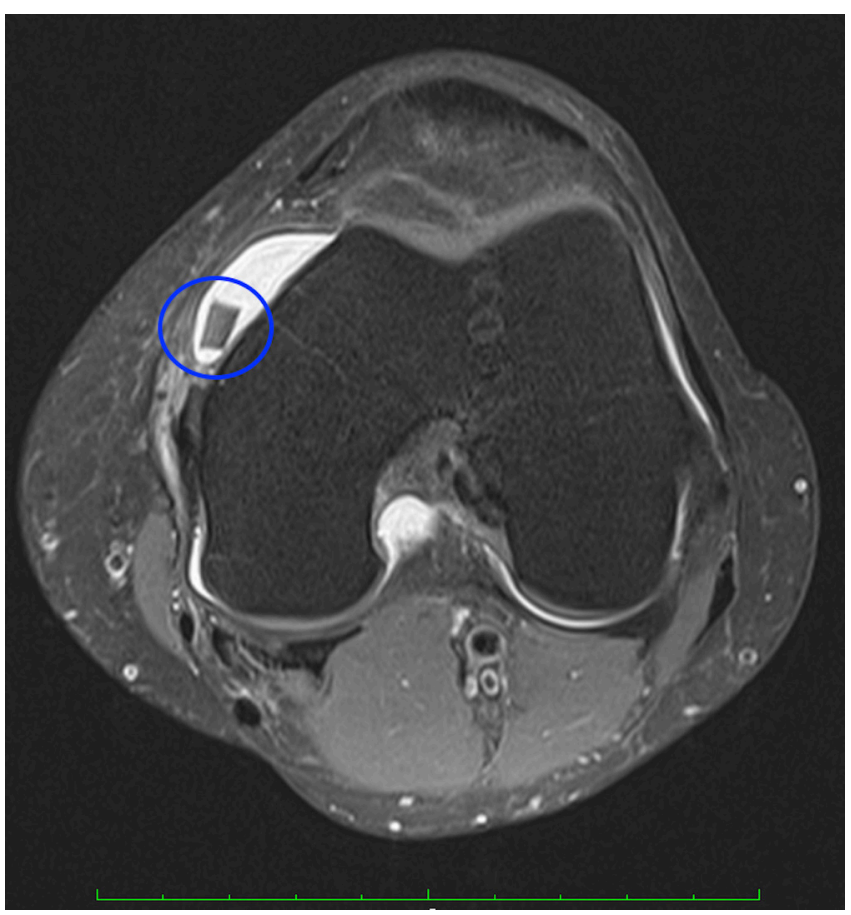

Figure 2 Proton density fat-suppressed MRI of the knee showing a loose chondral body in the medial femoral gutter. 


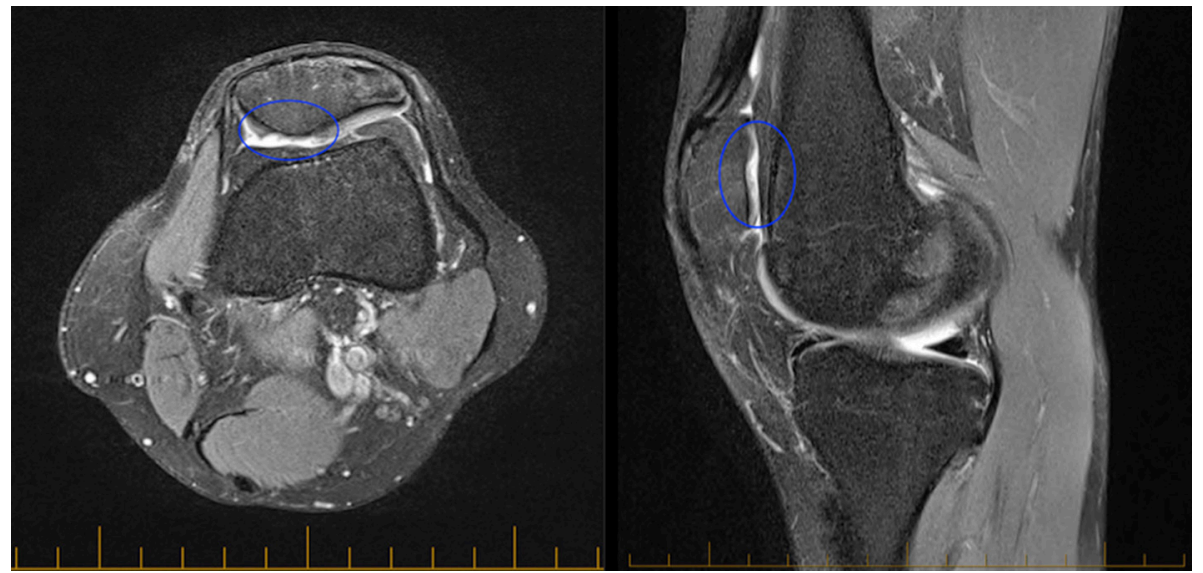

Figure 3 Pretreatment proton density fat-suppressed axial and sagittal MRI of the knee showing the isolated chondral defect involving the medial facet of the patella.

motion exercises and rehabilitation were instructed and guided by a treating physiotherapist.

Despite progressive and directed rehabilitation, the patient had persistent patellofemoral discomfort 9 months following her injury. She was unable to return to karate and was significantly limited in her occupation as a personal trainer. After consultation with a sports physician, the patient trialled a course of autologous platelet-rich plasma with no observed symptomatic improvement after completing a course of three injections. Repeat MRI indicated a persistent patella chondral defect measuring $12 \mathrm{~mm}$ at its widest diameter (figure 3 ).

After careful consideration, and due to persistent pain and dysfunction 12 months following her initial injury, the patient underwent a repeat arthroscopy with the intention of arthroscopic microfracture to the area of full-thickness chondral loss with planned postoperative autologous adipose-derived MSC (ADMSC) therapy. At the time of arthroscopy, a thin layer of fibrocartilage was noted at the base of the chondral defect and a decision was made not to disrupt this layer with microfracture (figure 4). The patient later underwent intra-articular injections of autologous ADMSCs.

Whilst alternative treatment using MACI was considered, it was felt that due to factors including donor site morbidity,

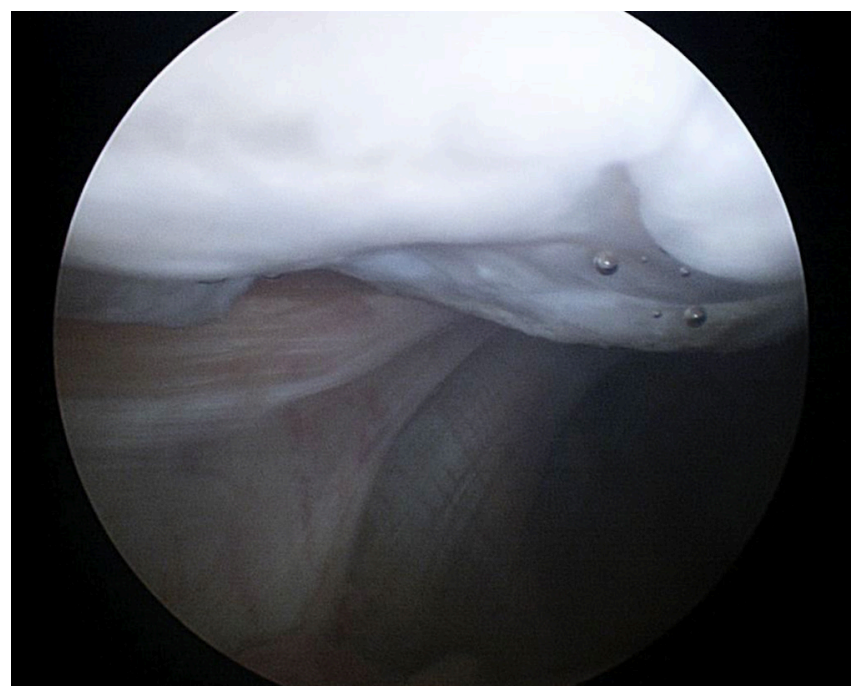

Figure 4 Arthroscopic picture of the isolated patella chondral injury showing a thin layer of fibrocartilage. difficulty of surgery and chondral defect site, that MACIwould be trialled only if ADMSC therapy failed.

The patient received written information regarding the use of MSC therapy, including the documented relative risks. Formal written consent was completed prior to commencement of treatment.

\section{INVESTIGATIONS}

See the Case presentation section.

\section{TREATMENT}

\section{Autologous adipose-derived MSC preparation}

\section{Source of MSCs}

Adipose tissue was chosen as a source of autologous MSCs due to the observed comparative chondrogenic ability of adipose versus bone marrow-derived MSCs, the relative abundance of MSCs within adipose tissue and the ease of harvest. ${ }^{9}{ }^{42}$ While bone marrow aspirate was considered as an alternative cell source, it has a paucity of MSCs-comprising $0.001 \%-0.02 \%$ of the mono-nucleated cell population, in comparison to $\sim 1 \%-7 \%$ of the mono-nucleated cell population within adipose tissue. ${ }^{910}$

\section{Harvest procedure}

The patient underwent an abdominal lipoharvest procedure. A single dose of prophylactic antibiotics was administered prior to commencement of the lipoharvest in accordance with accepted routine clinical practice. ${ }^{43}$

Tumescent fluid comprising $30 \mathrm{~mL}$ of $2 \%$ lignocaine, $1 \mathrm{~mL}$ of $1: 1000$ epinephrine and $1 \mathrm{~mL}$ of $8.4 \%$ bicarbonate suspended in normal saline (a total of $1000 \mathrm{~mL}$ ) was prepared. Three hundred millilitres of this preparation was infiltrated to the abdominal subcutaneous fat plane using a blunt tumescence cannula. Using a $3 \mathrm{~mm}$ lipo-aspirate cannula, $65 \mathrm{~mL}$ of lipoaspirate (adipose tissue and tumescent fluid) was aspirated and collected in a sterile single use Shippert Tissu-Trans Collection filter (Shippert Medical, Centennial, Colorado, USA). The lipoaspirate was transferred directly to a clean room laboratory from the theatre via a pass through hatch with an air lock system.

\section{Isolation and expansion of MSCs}

Isolation and expansion of autologous ADMSCs was undertaken using techniques that have been previously published. ${ }^{44}$ Processing of the lipoaspirate was performed under strict sterile conditions within a Biological Safety Cabinet Class II and within 

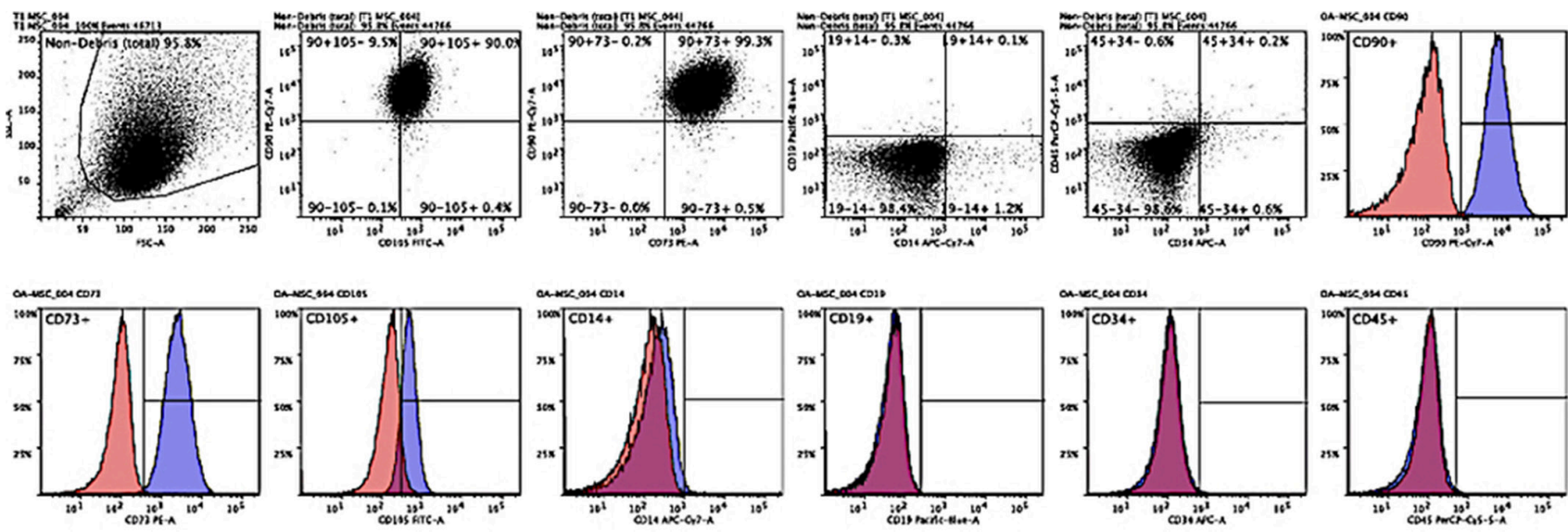

Figure 5 Flow cytometry dot-plot and histogram surface marker analysis. The pink and purple histograms represent isotope control and the tested cell sample, respectively. The cell population was positive for CD90, CD73 and CD105 and negative for CD14, CD19, CD34 and CD45 surface markers. Dot blot analysis indicated that $90.09 \%$ of cells were positive for CD90 and CD105, whereas $99.3 \%$ of cells were positive for CD90 and CD73. Furthermore, only $0.1 \%$ of cells expressed CD19 and CD14 surface markers and similarly $0.2 \%$ expressed both CD45 and CD34.

a clean room laboratory with equivalent ISO 5 or above air quality.

Stromal vascular fraction (SVF) was isolated from the harvested adipose tissue using enzymatic digestion and centrifugation. The SVF was then culture purified under hypoxic conditions within standard growth media containing 10\% fetal bovine serum (FBS) (HyClone-GE Healthcare, Chicago, Illinois, USA). Non-adherent cells were removed by washing with sterile phosphate-buffered saline (PBS) and adherent cells further cultured until $80 \%$ confluency. Cells were harvested at passage 0 (P0) and further plated to tissue culture flasks and expanded up to passage 2 (P2). At completion of P2, cells were harvested, washed three times to remove FBS and cryopreserved in clinical-grade qualified MSC cryoprotectant media using a validated control rate freezing method of $1^{\circ} \mathrm{C} / \mathrm{min} .^{4546}$ The cryovials were stored in liquid nitrogen until use.

\section{Characterisation and sterility testing}

Characterisation of the isolated cell population was confirmed using standards established by the International Society of Cellular Therapy. ${ }^{47}$ Phenotypic analysis using a flow cytometry Fluorescence-activated cell sorting (FACS) technique was performed independently at Monash University. Using fluorescent-labelled antibodies, a sample of the isolated cell population was assessed for the presence of MSC surface markers CD90, CD73 and CD105 and absence of haematopoietic surface markers CD14, CD19, CD34 and CD45 (figure 5 and table 1).

A cell sample was sent for independent sterility testing for microbial growth/contamination.

\section{Injection method}

Prior to injection, the stored cells were thawed using a sterile water bath with the cyroprotectant media separated from the stem cells using both centrifugation and washing in chilled
PBS. The cell pellet was resuspended in injectable clinical-grade isotonic $(0.9 \%)$ normal saline to a total of $3 \mathrm{~mL}$. Cell number and viability was confirmed using a Muse Cell Analyzer (Merck Millipore, Billerica, Massachusetts, USA). The MSC preparation was injected within $30 \mathrm{~min}$ of thawing.

The patient received intra-articular ADMSC therapy at 0 and 6 months.

At commencement of therapy, the patient received a total of 105 million ADMSCs (viability 94\%). The patient received a second injection of 112 million ADMSCs (viability 97.8\%) at 6 months.

At both times of injection, the patient's knee was prepped using standard sterile procedural protocols. Two millilitres of $1 \%$ lignocaine was infiltrated to the subcutaneous tissue at the site of the injection. Using ultrasound guidance and under aseptic conditions, the autologous ADMSCs suspended within $3 \mathrm{~mL}$ of normal saline was injected into the intra-articular knee space.

\section{Postinjection rehabilitation}

The patient was given postinjection rehabilitation guidelines including range of motion and muscle activation exercises. They were allowed to weight bear as tolerated. A formal strengthening programme was commenced under physiotherapist supervision.

\section{Analysis method and outcome measures}

The patient completed validated outcome questionnaires using the software programme Clinical Intelligence (Clinical Intelligence, Melbourne, Australia). Outcome measures were completed at baseline, 1, 3, 6, 9 and 12 months. These measures included:

- The Knee Injury and Osteoarthritis Outcome Score (KOOS). This validated score consists of five subscales: pain, symptoms, function in daily living, function in sport and recreation and knee-related quality of life. Standardised answers

Table 1 Flow cytometry fluorescence-activated cell sorting surface marker analysis showing results consistent with mesenchymal stem cells as per the International Society of Cellular Therapy guidelines

\begin{tabular}{|c|c|c|c|c|c|c|c|}
\hline & \multicolumn{3}{|c|}{ Histograms-positive markers } & \multicolumn{4}{|c|}{ Histogramsnegative markers } \\
\hline & CD90+ve & CD73+ve & CD105+ve & CD14+ve & CD19+ve & CD34+ve & CD45+ve \\
\hline Percentage & 99.47 & 99.58 & 88.57 & 1.27 & 0.27 & 0.81 & 0.86 \\
\hline
\end{tabular}


to questions are given using a 5 -point Likert scale, with each question assigned a score of $0-4$. A score is calculated for each subscale with 100 indicating no symptoms and 0 indicating maximum symptoms. ${ }^{48}$

- The Western Ontario and McMaster Universities Arthritis Index (WOMAC Index 3.0). This score is a validated quality of life score and quantitatively assesses the pain, stiffness and physical function in patients with symptomatic osteoarthritis. $^{49}$

- The Numeric Pain Rating Scale (NPRS). The patient is asked to rate their knee pain intensity over the previous week on a scale of $0-10$. The NPRS has been validated for use in people with knee osteoarthritis. ${ }^{50}$

Structural outcome was assessed using MRI and was performed prior to the commencement of therapy and again at 12 months follow-up. The cartilage defect was described using semiquantitative measures defined by a modified International Cartilage Repair Society (ICRS) score ${ }^{51}$ :

- Grade 0: normal cartilage

- Grade 1: focal blistering and intracartilaginous low-signal intensity area with an intact surface and bottom

- Grade 2: irregularities on the surface or bottom and loss of thickness of less than 50\%

- Grade 3: deep ulceration with loss of thickness of more than $50 \%$

- Grade 4: full-thickness cartilage wear with exposure of subchondral bone.

Cartilage quality was assessed using the validated non-invasive MRI technique of T2 relaxation time cartilage mapping. ${ }^{52}$ Previous publications have shown that increased cartilage water content reproducibly alters T2 relaxation time and is an indicator of abnormal cartilage pathology. ${ }^{53}$

\section{OUTCOME AND FOLLOW-UP}

\section{Pain and functional outcome}

Following commencement of ADMSC therapy, the patient experienced progressive improvement in pain with her NPRS improving from 8 at baseline to 2 within 3 months. This improvement remained consistent, although it had increased to 3 at conclusion of follow-up (figure 6).

Quality of life as recorded by the Global WOMAC score consistently improved with scores increasing from 64 at baseline to 92 at 12 months-a total improvement of 43\% (figure 7).

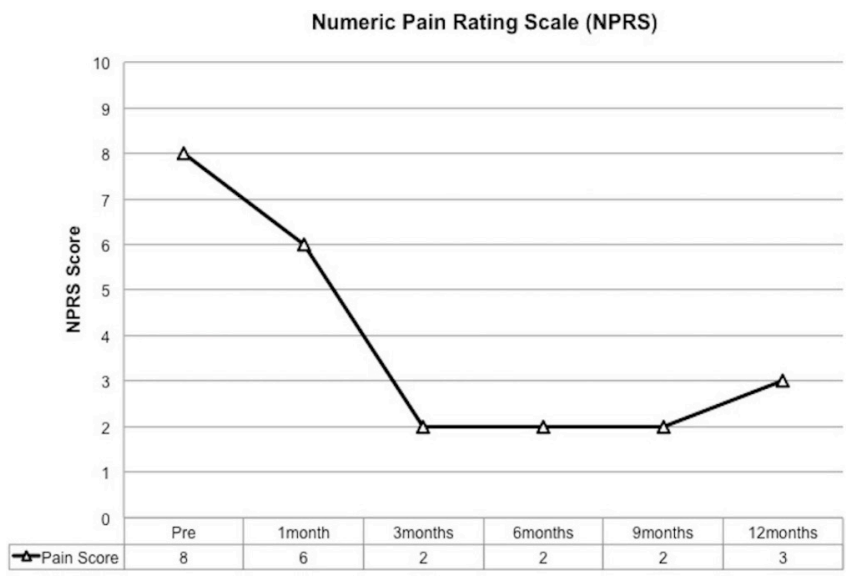

Figure 6 Numeric Pain Rating Score. Pain improved from commencement of therapy and remained improved until completion of follow-up at 12 months.

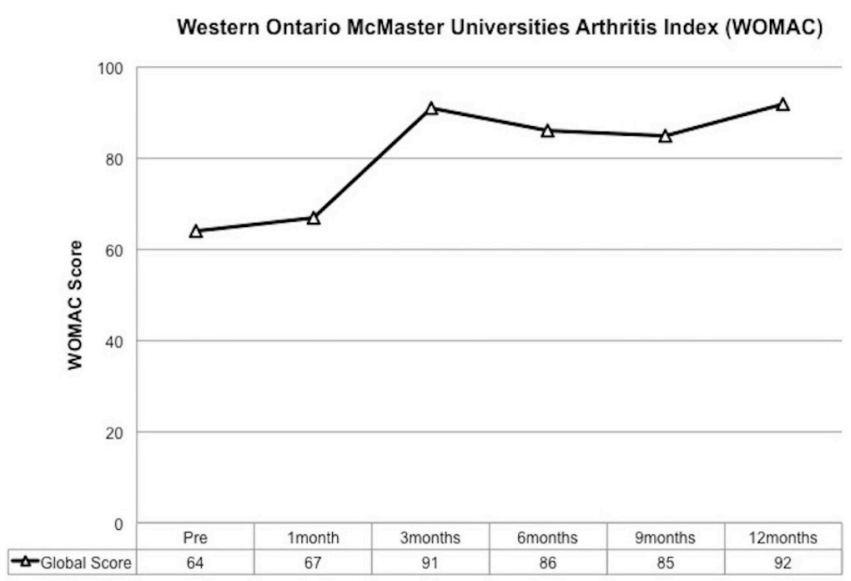

Figure 7 Western Ontario and McMaster Universities Arthritis Index. Pain, stiffness and function improved following mesenchymal stem cell therapy.

Reflecting the improvement observed in the WOMAC score, all separate KOOS parameters showed improvement across the follow-up period (figure 8). At 12 months, the symptom score had improved by over $635 \%$ and similarly sport and recreation by $700 \%$. Quality of life as measured by KOOS improved by $41 \%$ showing consistency in comparison to the WOMAC score.

\section{Structural outcome}

Structural follow-up using MRI showed significant improvement with complete filling of the chondral defect. The modified ICRS score, improved from Grade 3 to Grade 0 with smooth integration between the new cartilage and the surrounding native cartilage (figure 9).

T2-mapping techniques showed consistent values $<40$ through the deep and superficial areas of the regenerated tissue. This indicated normal hyaline-like cartilage morphology (figure 10).

\section{Complications and adverse events}

There were no significant complications documented during the course of treatment. The patient experienced mild bruising at the site of abdominal liposuction, which resolved within 4 weeks. Furthermore, the patient experienced pain and swelling of the knee following both the 0 -month and 6-month intra-articular ADMSC injections. These episodes were self-limiting,

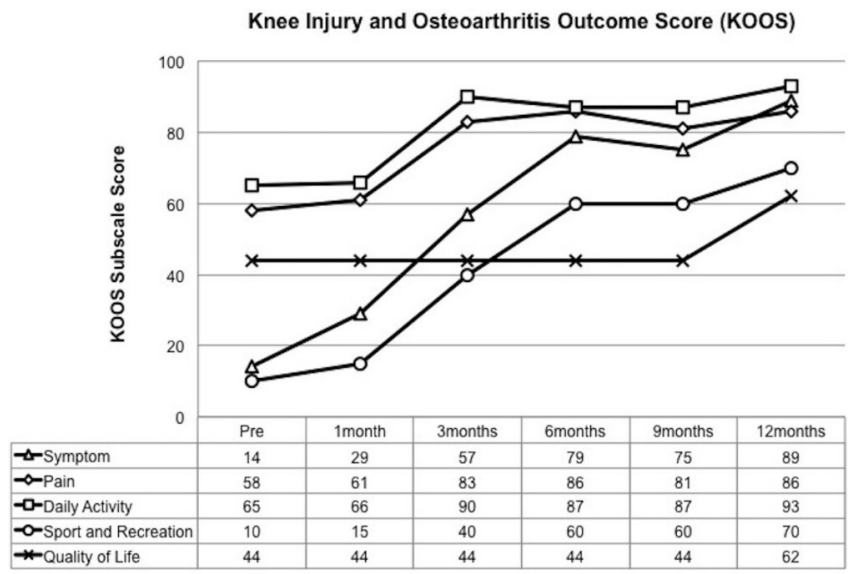

Figure 8 Knee Injury and Osteoarthritis Outcome Score. All subscales of KOOS showed progressive improvement over the period of follow-up. 


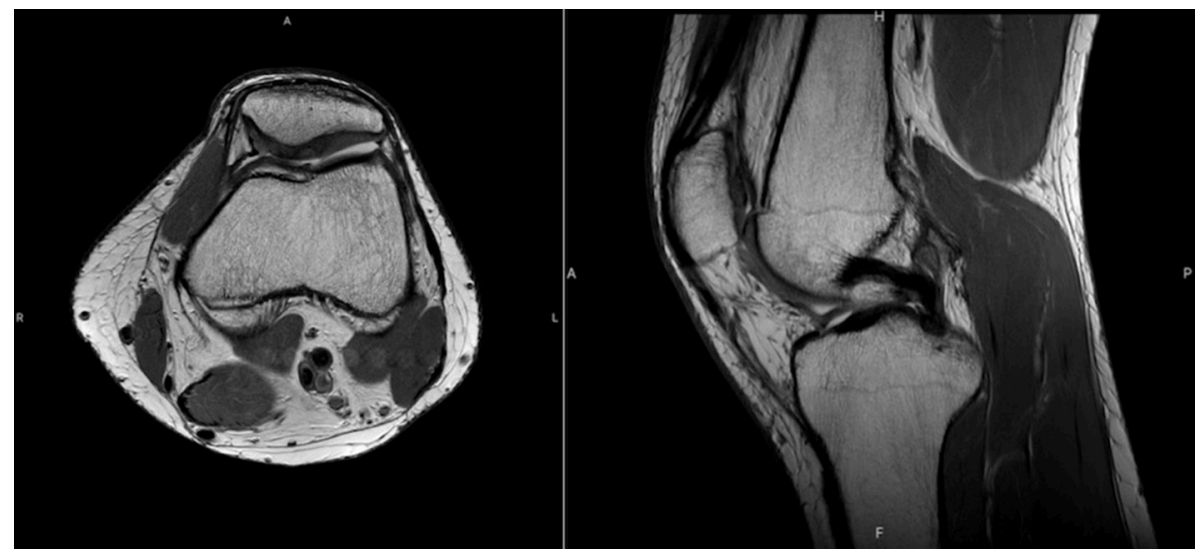

Figure 9 Post-treatment proton density axial and sagittal MRI indicating articular cartilage regeneration at the site of the chondral defect with smooth integration with the surrounding joint surface.

lasting 1 week and required only simple analgaesia. No serious adverse events were observed.

\section{DISCUSSION}

This case study shows the successful management of a post-traumatic chondral defect using intra-articular autologous ADMSC therapy. The patient had previously failed to have symptomatic improvement following a course of autologous platelet-rich plasma.

Current techniques for the treatment of isolated chondral defects include arthroscopic microfracture and ACI. Microfracture is limited due to observed fibrocartilage formation and poor long-term outcome. ${ }^{5-7}$ ACI techniques, while having noted reasonable long-term success, are limited by issues including surgical difficulty, donor site morbidity, poor integration with surrounding tissue and chondrocyte hypertrophy. ${ }^{16} 54$ Furthermore, the location of this patient's chondral defect, the medial facet of the patella, has not been associated with reproducible improvement following ACI intervention. ${ }^{17}$

The initial intention was to treat the patient using a combined microfracture and MSC therapy protocol similar to that

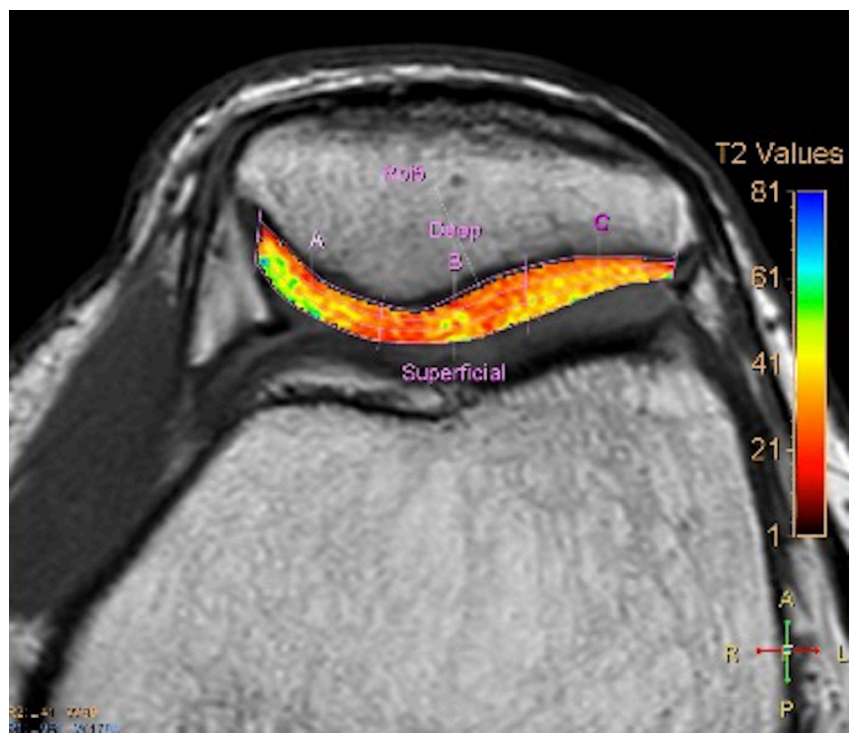

Figure 10 Post-treatment MRI T2 mapping of the patella. Values within the deep, middle and superficial layers of $<40$ indicate hyaline cartilage morphology. which has previously been published and which the authors are conducting a current RCT. ${ }^{39} 40$ Surprisingly, at the time of arthroscopy, there was an observed thin layer of fibrocartilage at the base of the chondral defect and it was chosen not to disrupt this area with microfracture.

Following commencement of ADMSC therapy, quantitative pain and functional outcome assessment using validated questionnaires all showed consistent improvement across the course of follow-up. This improvement was mirrored by structural improvements observed on MRI with complete fill of the chondral defect and smooth integration with the surrounding native cartilage. Complications not uncommon to current surgical management techniques such as $\mathrm{ACI} / \mathrm{MACI}$ or microfractureincluding poor tissue integration, tissue overgrowth and osseous formation-were not observed.

MRI T2-mapping techniques indicated normal hyaline-like cartilage regeneration with values similar to native cartilage. Past research has confirmed a significant correlation between comparable T2-mapping values of repair tissue and native cartilage and long-term positive outcome. ${ }^{55}$ The apparent robust chondrogenesis seen with ADMSCs in this case study is in contrast to prior in vitro analysis, which has indicated greater cartilaginous tissue deposition associated with bone marrow-derived MCSs over ADMSCs. ${ }^{56}$ While it is accepted that an arthroscopic biopsy would have provided definitive proof of cartilage histopathology, this invasive investigation was not felt to be justifiable due to the significant improvement in the patient's symptoms.

No serious adverse events were recorded during the follow-up period of 12 months. A self-limited flare up in pain was noted and is consistent with observations made in past clinical studies and suggests that intra-articular MSC injections are well tolerated. ${ }^{39}$

Current management of isolated chondral defects includes surgical interventions that are associated with patient comorbidity (ie, chondral biopsy), complications and unpredictable long-term outcome. Prior published reparative methods involving MSCs have used similar surgical cointerventions (microfracture) or transplantation techniques similar to ACI/MACI, whereby chondrocytes are replaced with MSCs. While past preclinical studies have indicated the ability of intra-articular injections to assist in cartilage healing, this is the first documented clinical case report of the successful use of this minimally invasive technique in the management of isolated chondral defects.

Whether MSCs directly differentiate into chondrocytes and rebuild cartilage is yet to be confirmed. Past studies have failed to consistently show integration of MSCs within articular cartilage 
and this suggests that the action of MSCs may be more through cellto-cell contact and paracrine mechanisms. ${ }^{24} 315758$ The observed limited layer of fibrocartilage at site of injury at arthroscopy and later robust cartilage regrowth after MSC therapy indicates the ability of MSCs to manipulate and amplify a reparative pathway.

It should be recognised that conclusions from this case are limited by the nature of a singular case study and they may not be reflected in a more vigorous and expansive controlled trial. Furthermore, the lesion was subacute with the traumatic chondral initial injury 12 months prior. Whether intra-articular MSC injections at the time of injury result in the same response or defects at other locations within the knee respond similarly is yet to be determined.

In this limited case study, the use of autologous ADMSC intra-articular injections, following a traumatic chondral defect of the patella, resulted in significant pain and functional improvements and importantly complete regeneration of hyaline-like cartilage within the defect. This is an extremely encouraging finding and unique to this study. The procedure was well tolerated with no serious adverse events recorded. This offers an exciting possibility in the minimally invasive management of post-traumatic chondral lesions without the observed limitations associated with current surgical management options including microfracture or ACI/MACI techniques.

This case study demonstrates the possible benefits of MSC therapy in musculoskeletal conditions and highlights the importance of further well-structured research in this area.

Learning points

- Post-traumatic chondral defects predispose to the development of generalised degenerative osteoarthritis.

- Current surgical methods for the treatment of isolated chondral defects are limited by surgical difficulty, patient morbidity and inconsistent long-term outcome.

- Mesenchymal stem cell therapy may offer an exciting potential in the treatment of chondropathology with observed structural regeneration in initial clinical translational research.

Acknowledgements The authors would like to acknowledge the following people for their contribution to the case study : Dr Paul Marks and Dr Chris Holden (Radiologists) for radiological analysis; Dr Dan Bates and Dr Leesa Huguenin for assistance in development of the treatment protocol; Dr Adele Barnard (Research Fellow at Clinical Intelligence) and Renee Castelluccio for assistance in data acquisition.

Contributors JF, DL, JW, KS and AT were involved in the data acquisition, analysis of data and drafting of the report. JF, DL, JW, KS and AT have read and approved the final manuscript. JF, DL, JW, KS and AT agreed to be accountable for the article and to ensure that all questions regarding the integrity of the article are investigated and resolved.

Competing interests JF is affiliated with Magellan Stem Cells and is a member of Magellan Stem Cells Clinical and Scientific Advisory Board. KS is affiliated with Magellan Stem Cells and is the Chief Scientific Officer of Magellan Stem Cells. AT is affiliated with Magellan Stem Cells.

Patient consent Obtained.

Provenance and peer review Not commissioned; externally peer reviewed.

Open Access This is an Open Access article distributed in accordance with the Creative Commons Attribution Non Commercial (CC BY-NC 4.0) license, which permits others to distribute, remix, adapt, build upon this work non-commercially, and license their derivative works on different terms, provided the original work is properly cited and the use is non-commercial. See: http://creativecommons.org/ licenses/by-nc/4.0/

(C) BMJ Publishing Group Ltd (unless otherwise stated in the text of the article) 2017. All rights reserved. No commercial use is permitted unless otherwise expressly granted.

\section{REFERENCES}

1 Buckwalter JA, Mankin HJ. Articular cartilage. Part II: degeneration and osteoarthrosis, repair, regeneration and transplantation. J Bone Joint Surg Am 1997:79:612-32.

2 Farnworth L. Osteochondral defects of the knee. Orthopedics 2000;23:146-57.

3 Prakash D, Learmonth D. Natural progression of osteo-chondral defect in the femoral condyle. Knee 2002;9:7-10.

4 Bhosale AM, Richardson JB. Articular cartilage: structure, injuries and review of management. Br Med Bull 2008;87:77-95.

5 Steadman JR, Briggs KK, Rodrigo JJ, et al. Outcomes of microfracture for traumatic chondral defects of the knee: average 11-year follow-up. Arthroscopy 2003; 19:477-84

6 Jakobsen RB, Engebretsen L, Slauterbeck JR. An analysis of the quality of cartilage repair studies. J Bone Joint Surg Am 2005;87:2232-9.

7 Magnussen RA, Dunn WR, Carey JL, et al. Treatment of focal articular cartilage defects in the knee: a systematic review. Clin Orthop Relat Res 2008;466:952-62.

8 Hunt SA, Sherman 0. Arthroscopic treatment of osteochondral lesions of the talus with correlation of outcome scoring systems. Arthroscopy 2003:19:360-7.

9 Peng $L$, Jia Z, Yin $X$, et al. Comparative analysis of mesenchymal stem cells from bone marrow, cartilage, and adipose tissue. Stem Cells Dev 2008:17:761-74.

10 Alvarez-Viejo M, Menendez-Menendez Y, Blanco-Gelaz MA, et al. Quantifying mesenchymal stem cells in the mononuclear cell fraction of bone marrow samples obtained for cell therapy. Transplant Proc 2013;45:434-9.

11 Brittberg M, Lindahl A, Nilsson A, et al. Treatment of deep cartilage defects in the knee with autologous chondrocyte transplantation. N Engl J Med 1994;331:889-95.

12 Brittberg M, Nilsson A, Lindahl A, et al. Rabbit articular cartilage defects treated with autologous cultured chondrocytes. Clin Orthop Relat Res 1996;326:270-83.

13 Chiang H, Kuo TF, Tsai CC, et al. Repair of porcine articular cartilage defect with autologous chondrocyte transplantation. J Orthop Res 2005;23:584-93.

14 Rahfoth B, Weisser J, Sternkopf F, et al. Transplantation of allograft chondrocytes embedded in agarose gel into cartilage defects of rabbits. Osteoarthritis Cartilage 1998:6:50-65.

15 Peterson L, Minas T, Brittberg M, et al. Two- to 9-year outcome after autologous chondrocyte transplantation of the knee. Clin Orthop Relat Res 2000;374:212-34.

16 Ahsan T, Lottman LM, Harwood F, et al. Integrative cartilage repair: inhibition by betaaminopropionitrile. J Orthop Res 1999:17:850-7.

17 Niemeyer P, Steinwachs M, Erggelet C, et al. Autologous chondrocyte implantation for the treatment of retropatellar cartilage defects: clinical results referred to defect localisation. Arch Orthop Trauma Surg 2008;128:1223-31.

18 Barry FP, Murphy JM. Mesenchymal stem cells: clinical applications and biological characterization. Int J Biochem Cell Biol 2004:36:568-84.

19 Arinzeh TL. Mesenchymal stem cells for bone repair: preclinical studies and potential orthopedic applications. Foot Ankle Clin 2005;10:651-65.

20 Noël D, Djouad F, Jorgense C. Regenerative medicine through mesenchymal stem cells for bone and cartilage repair. Curr Opin Investig Drugs 2002:3:1000-4.

21 Longobardi L, O'Rear L, Aakula S, et al. Effect of IGF-I in the chondrogenesis of bone marrow mesenchymal stem cells in the presence or absence of TGF-beta signaling. I Bone Miner Res 2006:21:626-36.

22 Diekman BO, Rowland CR, Lennon DP, et al. Chondrogenesis of adult stem cells from adipose tissue and bone marrow: induction by growth factors and cartilage-derived matrix. Tissue Eng Part A 2010;16:523-33.

23 Kern S, Eichler H, Stoeve J, et al. Comparative analysis of mesenchymal stem cells from bone marrow, umbilical cord blood, or adipose tissue. Stem Cells 2006;24:1294-301.

24 Caplan Al. Why are MSCs therapeutic? New data: new insight. J Pathol 2009;217:318-24

25 Mitchell PG, Magna HA, Reeves LM, et al. Cloning, expression, and type II collagenolytic activity of matrix metalloproteinase-13 from human osteoarthritic cartilage. J Clin Invest 1996:97:761-8.

26 Goldring MB. Osteoarthritis and cartilage: the role of cytokines. Curr Rheumatol Rep 2000;2:459-65.

27 Sandell LJ, Aigner T. Articular cartilage and changes in arthritis. An introduction: cell biology of osteoarthritis. Arthritis Res 2001;3:107-13

28 Caplan Al, Correa D. The MSC: an injury drugstore. Cell Stem Cell 2011:9:11-15.

29 Caplan Al. Mesenchymal stemcells. J Orthop Res 1991;9:641-50.

30 Nakagami H, Morishita R, Maeda K, et al. Adipose tissue-derived stromal cells as a novel option for regenerative cell therapy. J Atheroscler Thromb 2006;13:77-81.

31 Wu L, Leijten JC, Georgi N, et al. Trophic effects of mesenchymal stem cells increase chondrocyte proliferation and matrix formation. Tissue Eng Part A 2011;17:1425-36

32 Grigolo B, Lisignoli G, Desando G, et al. Osteoarthritis treated with mesenchymal stem cells on hyaluronan-based scaffold in rabbit. Tissue Eng Part C Methods 2009;15:647-58. 
33 Cui L, Wu Y, Cen L, et al. Repair of articular cartilage defect in non-weight bearing areas using adipose derived stem cells loaded polyglycolic acid mesh. Biomaterials 2009;30:2683-93.

34 Saw KY, Hussin P, Loke SC, et al. Articular cartilage regeneration with autologous marrow aspirate and hyaluronic Acid: an experimental study in a goat model. Arthroscopy 2009;25:1391-400.

35 Mcllwraith CW, Frisbie DD, Rodkey WG, et al. Evaluation of intra-articular mesenchymal stem cells to augment healing of microfractured chondral defects. Arthroscopy 2011;27:1552-61.

36 Lee $\mathrm{KB}$, Hui JH, Song IC, et al. Injectable mesenchymal stem cell therapy for large cartilage defects-a porcine model. Stem Cells 2007;25:2964-71.

37 Wakitani S, Imoto K, Yamamoto T, et al. Human autologous culture expanded bone marrow mesenchymal cell transplantation for repair of cartilage defects in osteoarthritic knees. Osteoarthritis Cartilage 2002;10:199-206.

38 Nejadnik H, Hui JH, Feng Choong EP, et al. Autologous bone marrow-derived mesenchymal stem cells versus autologous chondrocyte implantation: an observational cohort study. Am J Sports Med 2010;38:1110-6.

39 Saw KY, Anz A, Siew-Yoke Jee C, et al. Articular cartilage regeneration with autologous peripheral blood stem cells versus hyaluronic acid: a randomized controlled trial. Arthroscopy 2013;29:684-94.

40 Freitag J, Ford J, Bates D, et al. Adipose derived mesenchymal stem cell therapy in the treatment of isolated knee chondral lesions: design of a randomised controlled pilot study comparing arthroscopic microfracture versus arthroscopic microfracture combined with postoperative mesenchymal stem cell injections. BMJ Open 2015;5:e009332.

41 US National Institutes of Health. ClinicalTrials.gov. ClinicalTrials.govhttp://clinicaltrials. gov/ct2/results?term=mesenchymal+stem+cells\&Sea $r c h=S e a r c h$ (accessed Jun 2014).

42 Im Gl, Shin YW, Lee KB. Do adipose tissue-derived mesenchymal stem cells have the same osteogenic and chondrogenic potential as bone marrow-derived cells? Osteoarthritis Cartilage 2005;13:845-53.

43 Messingham MJ, Arpey CJ. Update on the use of antibiotics in cutaneous surgery. Dermatol Surg 2005;31:1068-78.

44 Zuk PA, Zhu M, Mizuno H, et al. Multilineage cells from human adipose tissue: implications for cell-based therapies. Tissue Eng 2001;7:211-28.

45 Martinello T, Bronzini I, Maccatrozzo L, et al. Canine adipose-derived-mesenchymal stem cells do not lose stem features after a long-term cryopreservation. Res Vet Sci 2011;91:18-24
46 Goh BC, Thirumala S, Kilroy G, et al. Cryopreservation characteristics of adiposederived stem cells: maintenance of differentiation potential and viability. J Tissue Eng Regen Med 2007;1:322-4.

47 Dominici M, Le Blanc K, Mueller I, et al. Minimal criteria for defining multipotent mesenchymal stromal cells. The international society for cellular therapy position statement. Cytotherapy 2006;8:315-7.

48 Roos EM, Roos HP, Lohmander LS, et al. Knee Injury and Osteoarthritis Outcome Score (KOOS)-development of a self-administered outcome measure. J Orthop Sports Phys Ther 1998;28:88-96.

49 Bellamy N, Buchanan WW, Goldsmith CH, et al. Validation study of WOMAC: a health status instrument for measuring clinically important patient relevant outcomes to antirheumatic drug therapy in patients with osteoarthritis of the hip or knee. J Rheumatol 1988;15:1833-40.

50 Dworkin RH, Turk DC, Farrar JT, et al. IMMPACT. Core outcome measures for chronic pain clinical trials: IMMPACT recommendations. Pain 2005:113:9-19.

51 Brittberg M, Winalski CS. Evaluation of cartilage injuries and repair. J Bone Joint Surg Am 2003;85(suppl 2):58-69.

52 Crema MD, Roemer FW, Marra MD, et al. Articular cartilage in the knee: current MR imaging techniques and applications in clinical practice and research. Radiographics 2011;31:37-61.

53 Mamisch TC, Trattnig S, Quirbach S, et al. Quantitative T2 mapping of knee cartilage: differentiation of healthy control cartilage and cartilage repair tissue in the knee with unloading-initial results. Radiology 2010;254:818-26.

54 von der Mark K, Gauss V, von der Mark H, et al. Relationship between cell shape and type of collagen synthesised as chondrocytes lose their cartilage phenotype in culture. Nature 1977;267:531-2.

55 Krusche-Mandl I, Schmitt B, Zak L, et al. Long-term results 8 years after autologous osteochondral transplantation: $7 \mathrm{~T}$ gagCEST and sodium magnetic resonance imaging with morphological and clinical correlation. Osteoarthritis Cartilage 2012;20:357-63.

56 Kohli N, Wright KT, Sammons RL, et al. An in vitro comparison of the incorporation, growth, and chondrogenic potential of human bone marrow versus adipose tissue mesenchymal stem cells in clinically relevant cell scaffolds used for cartilage repair. Cartilage 2015;6:252-63.

57 Jing XH, Yang L, Duan XJ, et al. In vivo MR imaging tracking of magnetic iron oxide nanoparticle labeled, engineered, autologous bone marrow mesenchymal stem cells following intra-articular injection. Joint Bone Spine 2008;75:432-8

58 Mokbel AN, El Tookhy OS, Shamaa AA, et al. Homing and reparative effect of intraarticular injection of autologus mesenchymal stem cells in osteoarthritic animal model. BMC Musculoskelet Disord 2011;12:1.

Copyright 2017 BMJ Publishing Group. All rights reserved. For permission to reuse any of this content visit

http://group.bmj.com/group/rights-licensing/permissions.

BMJ Case Report Fellows may re-use this article for personal use and teaching without any further permission.

Become a Fellow of BMJ Case Reports today and you can:

- Submit as many cases as you like

- Enjoy fast sympathetic peer review and rapid publication of accepted articles

- Access all the published articles

- Re-use any of the published material for personal use and teaching without further permission

For information on Institutional Fellowships contact consortiasales@bmjgroup.com

Visit casereports.bmj.com for more articles like this and to become a Fellow 